Evidence-Based Practice Center, Robert D. and Patricia E. Kern Center for the Science

\title{
Breathe: surgical interventions in pulmonary diseases
}

Cite as: Dobler CC. Breathe: surgical interventions in pulmonary diseases. Breathe 2018; 14: 262-263. (c) ERS 2018
This is my first issue of Breathe as the new Chief Editor and I would like to take the opportunity to thank Renata Riha, the outgoing Chief Editor, for the outstanding work she has done over the past 3 years. Under her leadership, Breathe established a strong online presence, introduced new features such as the Physiology masterclass and the Radiology corner, and strengthened the journal's collaboration with the European Respiratory Society Early Career Members Committee. Today, Breathe is a leader in providing practice-focused educational content to respiratory professionals.

Over the next 3 years of my mandate, the aim will be to continue providing evidence-based information to inform clinical practice, to highlight current controversies, and interpret emerging topics and breakthroughs in respiratory medicine with regards to their relevance for respiratory clinicians.

We have added several new features to Breathe. The Patient voice articles are short pieces written by patients, patient advocates or carers that highlight the patient perspective. The articles are produced in collaboration with the European Lung Foundation, but independent spontaneous submissions are also welcome. In this issue we hear about a patient's experience with lung transplantation [1].

Additional space will be given to the discussion of lung function testing in the Lung function corner, which contains articles that typically present a clinical case scenario with the results of a lung function test (e.g. spirometry, methacholine challenge tests, cardiopulmonary exercise tests, lung clearance index and forced oscillation technique). Pierantonio Laveneziana and Andrea Aliverti are the section editors for the new Lung function corner. Together with co-authors they have written the inaugural Lung function corner article in this issue [2].

Another new feature in Breathe are the Journal club articles, which provide a concise summary and discussion of a recently published important study relevant to respiratory medicine. These articles provide great opportunities for contributions from early career researchers. In this issue we have Journal club articles on: treatment of asthma [3], treatment of COPD [4, 5], and mediastinal staging by videomediastinoscopy in nonsmall cell lung cancer [6].

The main focus of the December issue of Breathe is on surgical interventions in pulmonary diseases. Thoracic surgery including transplantation plays an important role in many lung diseases, and knowledge about surgical options is essential for respiratory clinicians who have to make decisions about when to refer patients to a thoracic surgeon and who follow-up patients after lung surgery. We have excellent reviews on: controversies and emerging topics in lung transplantation [7], a must-read for all respiratory professionals who would like to gain a better understanding of lung transplantation; minimally invasive thoracic surgery for empyema [8], providing a comprehensive overview of a topic of longstanding debate; and surgery in nontuberculous mycobacteria pulmonary disease [9], a summary of the available 
evidence on the topic, which is likely to become an important reference in this area.

Finally, I want to point to an article that provides helpful tips on how to write a response to the reviewers of your manuscript [10]. The acquired knowledge can directly be applied to your Breathe manuscript!

If you are interested in contributing an article to Breathe you can obtain more information on article types and specific requirements on the Breathe website in the "For authors" section (breathe.ersjournals.com/authors/instructions). We welcome spontaneous submissions for all article types except Journal club articles, which are generally commissioned. Suggestions for Journal club papers can, however, be addressed to the ERS publications office.

I recently learned that there is a Japanese word for having lots of unread literature piled up in one's home, Tsundoku, a condition that probably affects many of us. My hope is that Breathe will not end up on the "to-be-read pile" for the next few months or years, but that you will dig into the pages right away!

As we are approaching the end of the year, I would like to wish everyone a relaxing and reenergising festive season and a Happy New Year!

\section{Conflict of interest}

C.C. Dobler has nothing to disclose.

\section{References}

1. Francisco MJP. Lung transplantation. Breathe 2018; 14 276-277.

2. Laveneziana P, Niérat M-C, LoMauro A, et al. A case of unexplained dyspnoea: when lung function testing matters! Breathe 2018; 14: 325-332.

3. Lahousse L. Amazing pleiotropic effects of azithromycin. Breathe 2018; 14: 336-337.

4. Long G, Wall J. Precision medicine in COPD: review of mepolizumab for eosinophilic COPD. Breathe 2018; 14 : 338-341.

5. Dobler CC. The IMPACT of triple versus dual single-inhaler therapy on exacerbations of COPD. Breathe 2018; 14: 333-335.
6. Bostantzoglou C, Iliopoulou M, Hardavella G. Mediastinal staging by videomediastinoscopy in clinical N1 non-small cell lung cancer. Breathe 2018; 14: 342-344.

7. Abelson D, Glanville AR. Controversies and emerging topics in lung transplantation. Breathe 2018; 14: 278-287.

8. Subotic D, Lardinois D, Hojski A. Minimally invasive thoracic surgery for empyema. Breathe 2018; 14: 302-310.

9. Lu M, Fitzgerald D, Karpelowsky J, et al. Surgery in nontuberculous mycobacteria pulmonary disease. Breathe 2018; 14: 288-301.

10. Hiemstra PS. How to write a response to the reviewers of your manuscript. Breathe 2018; 14: 319-321. 